\title{
Metacognitive Strategies by Low Achieving Students in Reading Multimodal Texts
}

\author{
Theresia Manalu*, Yanty Wirza \\ Department of English Education, Universitas Pendidikan Indonesia, Bandung, Indonesia \\ *Corresponding author. Email: theresiamanalu@upi.edu
}

\begin{abstract}
Despite many findings of the consistent activation of metacognitive reading strategies by successful students on various reading texts, metacognitive reading strategies have been less investigated on low achieving students towards multimodal text modes. This paper attempts to explore the metacognitive reading strategies phenomenon of low proficient students towards visual, audio, and linguistic text composition in a public senior high school in Indonesia through a case study design. It investigated the tendency use of metacognitive reading strategies on each mode assigned. The data were collected from 68 EFL students by assigning reading comprehension tests and administering MARSI (Metacognitive Awareness Reading Strategy Inventory) questionnaire as the instruments in this study. The adapted and constructed reading comprehension tests were assigned to validate low students' representation and to stimulate students' metacognitive reading strategies. The modified MARSI (Metacognitive Awareness Reading Strategy Inventory) questionnaires were administered to examine the selected low proficient students' metacognitive reading strategies consisting of global reading strategies, problem-solving strategies, and support reading strategies. The results of weekly reading comprehension tests then were scored statistically to get the low scores cluster of the overall students. The inferential and descriptive analysis was carried out to define each subscale score of metacognitive reading strategies in the statistical findings. Findings show the similar metacognitive strategies were used among those three different assigned modes. The finding reveals that support reading strategies were considered to be the rarest used strategies. The detail information of each subscale use of each domain of metacognitive reading strategies was fully discussed.
\end{abstract}

Keywords: Audio representation, linguistic representation, metacognitive reading strategies, visual representation

\section{INTRODUCTION}

With Reading is typically considered as one of the essential skills for EFL/ESL students (Nunan, 2003). The demonstration of reading as one of skills should be mastered by the students, proceeds its existence in Indonesian EFL teaching and learning atmosphere in the concept of receptive skill (Al-Issa, 2006; Leu et al., 2011). The flowing process of meaning-making in reading comprehension involves the combination of information from a text and background knowledge in terms of schemata activation to construct meaning (Lander \& Brown, 1995; Nunan, 2003). For that purpose, Indonesian students are expected to be able to read strategically and meaningfully. However, the results of Indonesian students have not reached the expectations of Indonesian educational government. In fact, the Indonesian students' reading proficiency is categorized in low level based on several world surveys issuing reading culture and proficiency (Sinambela et al., 2015).

One of the initial disadvantages of Indonesian students, for example, is the absence of a variety of different types of texts and the level of text offered according to PISA as one of the most knowable world literacy assessment. The difficulties of Indonesian students in interpreting PISA questions can be shown by the results of some study attempt by a variety of practitioners. They observed that the characteristics of the texts in PISA's literacy questions were relatively lengthy and that the variables of graphics, tables or maps infused in the texts appeared to be complex. In depth, PISA infuses $52 \%$ of the tables, narration, formulas, graphics, and several other tools consisting of different semiotic modes. (Harsiati, 2018; Liu, 2013). It indicated the majority of texts in PISA's questions turns to be multimodal. 
In fact, the traditional texts have turned to be multimodal, consisting of various modes which becomes the texts generally integrated for 21 st century learning (Serafini, 2012). The existence of immersed various text forms reinforces the complexity of $21^{\text {st }}$-century representation between world and texts (Suherdi, 2015). This demand manifests the text immersed in reading instructions to expose today's real communicative context in which teachers are used to carrying out in case of reading texts. The nature of improving students' capability in terms of strategies in reading comprehension should be started from the students itself besides requiring teachers and students to read more because in this case, the main actor is certainly students on how they understand meaningfully various reading materials utilized in the classroom (Mohamed et al., 2006). In the meantime, to achieve a meaningful understanding of the particular reading passage, students indeed have difficulties getting ideas and information and unconsciously activating their strategies of prior knowledge in terms of schemata (Nguyen \& Newton, 2018).

In response, metacognitive reading strategy which involves two essential parts in the process of meaningmaking: students' cognition and reading strategy is recommended to be taught in EFL classroom. Metacognitive reading strategy can help students to read meaningfully in the process of reading because the activation of metacognition can propose students to their awareness of what they are reading successfully (Chen \& Chen, 2015). Even so, encouraging students to possess their reading strategies in overcoming their difficulties is one of teachers' tasks to conceptualize students' needs to comprehend and remember such kind of text by inferring information, elaborating ideas, and eliminating unnecessary details (Artelt et al., 2013).

Previous research has conducted the study about metacognition and reading comprehension. Mohamed, et al. (2006) aimed to recognize the comprehension and usage of metacognitive reading strategies of effective readers in Malaysia in order to highlight the importance of using reading strategies to involve students with critical understanding. They found that good Malaysian learners are aware of their own metacognitive strategy and frequently used that to comprehend texts. This study has revealed the important information of metacognitive reading strategy phenomenon among good learners, but it is lack in exploring this strategy among weak learners in reading comprehension. Next, Chevalier et al. (2017) tried to investigate the differences in the use of strategy and strategy as a predictive measure of students in reading performance who have completed online questionnaires on reading history and strategy use. The results then concluded that students who have a history of reading difficulties rarely applied their metacognitive strategies. This results then implied new horizon to the metacognitive reading strategies paradox in which psychology issues impacts to the students' metacognitive reading strategies frequency. As the response, the immersion of metacognition of reading comprehension contributively helps students to read meaningfully and strategically.

In conclusion, those problematic issues and empirical studies elaborated in the previous paragraphs, give the considerable insights to the present study. There have been many studies conducting research on students' variances and their metacognitive reading strategies. But there has been no study which investigates students' metacognitive reading strategies on different various text composition to the particular students' proficiency. In response, it is essential to conduct a research in case metacognitive reading strategies in multimodal text as the most recently used in 21 st century learning.

\section{METHOD}

A qualitative approach was conducted in this current research based on a case study design to investigate the phenomenon of the activated metacognitive reading strategies of low achieving students in reading three different multimodal text modes. $68 \mathrm{EFL}$ students participated during English virtual classes from one public school in Indonesia. All students were in the second grade of senior high school. Multimodality exposures in English subject materials has been the core reason for selecting this school to be the required data resources.

A stratified random sampling was used respectively from 68 students who were split into low achievers according to the stated norms of academic achievement. In this study, the target low achieving students included all secondary school students enrolled in 11th class who got less than $40 \%$ marks from students grading board (Anwar et al., 2012) based on the stated norms of academic achievement during three-week students' performance in reading comprehension tests, entry school test, and English teacher's judgment to obtain students' lens of low group. 10 low achievers then selected from stratified scores' cluster to be the respondents to carry out the MARSI questionnaires.

This study used reading comprehension tests and MARSI questionnaires to collect the overall data. The reading comprehension texts were adapted and constructed from online several resources. The three kinds of text modes of the selected reading comprehension texts talked about Dr. Martin Luther King, Jr as the compatibility of school's English reading materials and recommendation of the English teacher. The second instrument is MARSI questionnaires which was adapted and modified based each text mode.

Firstly, the reading comprehension tests were assigned to validate low students' representation and to stimulate students' metacognitive reading strategies 
while reading multimodal texts during English virtual classes. Then, MARSI questionnaires were administered to get a portrait of the most metacognitive reading strategies frequently use (Mokhtari \& Reichard, 2002) of each multimodal reading text mode after working with multiple reading comprehension tests. The results of MARSI questionnaire were analyzed statistically using Statistical Packages for the Social Sciences (SPSS), version 26.0 for Windows.

\section{RESULTS AND DISCUSSION}

This section answers the research questions of this study about the tendency to use metacognitive reading strategies by high achieving students and their purposes of activated the current strategy. The study results consist of qualitative and quantitative data to show the activated metacognitive reading strategies of the selected participants and the purpose they activated those strategies in comprehending the three multimodal texts shifted. The complete and detailed results of this study and its analysis are presented in the following finding and discussion.

\subsection{Metacognitive reading strategies frequently use}

\subsubsection{Visual Representation Mode}

The first type of text mode reveals a visual representation, indicating the visual semiotic mode of multimodal design in the purpose various communication modes of the brief explanation of Dr. Martin Luther King Jr biography in the context of video demonstration. The infused moving images in the video were revealed by the low achieving students through their reading strategies. Then the result in statistical findings in this kind of modes was elaborated respectively in the Table 1.

Table 1 shows that the low achieving students are aware of their metacognitive reading strategies while reading and using them frequently to monitor their reading comprehension towards visual text modes. In details, the problem-solving strategists have earned the highest average score $(\mathrm{M}=3.71)$ resulting in a high level of knowledge. It reveals that low achieving students have achieved an overwhelming choice for problem-solving strategy, which is more important than the two remaining strategies, the global reading strategy $(M=3.63)$, which has put the second level and proceeded to support reading strategies $(M=3.33)$ as the last stage in the stratification of numbers.
Table 1. Overall analysis of metacognitive reading strategies in visual representation

\begin{tabular}{ccc}
\hline $\begin{array}{c}\text { Reading Strategies } \\
\text { Subscale }\end{array}$ & $\begin{array}{c}\text { Overall Mean } \\
\text { (M) }\end{array}$ & $\begin{array}{c}\text { Overall Std. } \\
\text { Deviation (SD) }\end{array}$ \\
\hline $\begin{array}{c}\text { Global Reading } \\
\text { Strategies }\end{array}$ & 3.63 & 0.92 \\
$\begin{array}{c}\text { Problem Solving } \\
\text { Strategies }\end{array}$ & $\mathbf{3 . 7 1}$ & 0.75 \\
$\quad$ & & \\
Support Reading \\
Strategies
\end{tabular}

It also indicated that low achieving students activated their metacognitive reading strategies in high intention with a little bit different in numbers.

Moreover, it is found that low achieving students employed such kind of problem solving strategies more frequently than other strategies while reading visual text mode which allowed students to navigate their action plans through the text skillfully when the texts becomes difficult to understand. It includes how students re-read the text for better understanding, go back to the every sentence or paragraph, pause and stop while reading intended to read slowly and carefully and to adjust reading rate, visualize information obtained while reading, and many other activities which define problem solving strategies they employed to understand certain kind of text mode especially in visual text mode.

Those overall result then confirmed that in the practical use of strategies in reading text visual mode, low achieving students cohesively activate their strategy in frequent and effective ways appropriate to the visual texts. Looking deeper to the number of average use of certain strategies, problem solving and global reading strategies were activated more often when the students read visual text mode. This was reinforced by Mistar (2001), which performed an analysis of learning techniques through variations, which showed that both successful and less knowledgeable EFL students in Indonesia used common strategies when reading the text.

\subsubsection{Audio Representation}

In this part of this study, audio text mode is used in the form Dr Martin Luther King Jr audio speech only and the script is given in one set of audio text. The way on how low achieving students covers their metacognitive reading strategies to understand the meaning of the text assigned are revealed in Table 2. 
Table 2. Overall analysis of metacognitive reading strategies in audio representation

\begin{tabular}{ccc}
\hline $\begin{array}{c}\text { Reading Strategies } \\
\text { Subscale }\end{array}$ & $\begin{array}{c}\text { Overall Mean } \\
(\mathrm{M})\end{array}$ & $\begin{array}{c}\text { Overall Std. } \\
\text { Deviation (SD) }\end{array}$ \\
\hline $\begin{array}{c}\text { Global Reading } \\
\text { Strategies }\end{array}$ & 3.94 & 0.93 \\
Problem Solving \\
Strategies
\end{tabular}

According to the overall mean score of reading strategy, low achieving EFL students seem to be highly aware of their reading strategies based on the mean score they obtained which covering the higher number indicating that the students applied their reading strategy more frequently to their reflected particular strategy. However, this result confirmed that low achieving students made high preferences of problem-solving strategy as their reading resolution on reading audio text mode. It also revealed that the low level of achievement of the students in this research was directed towards a specific reading strategies based on their own self, which concerned the solution of reading when there is an issue of comprehension, such as changing the reading pace and paying more attention to the reading text. (Anderson, 2003; Mokhtari \& Reichard, 2002).

Accordingly, the descriptive statistics of Table 2 showed most frequent use of the metacognitive reading strategies of less achieving students. According to the overall mean of reading strategies for unsuccessful students, it was found that problem solving strategy was the most frequent use of the metacognitive reading strategy ( $M=4.00$, SD 0.67), followed by global reading strategy $(\mathrm{M}=3.94, \mathrm{SD} 0.93)$ and the last was support reading strategy $(\mathrm{M}=3.71, \mathrm{SD}=0.92)$. It also showed that low achieving students in reading audio text mode had focused their reading strategies, which concerned reading slowly but deliberately to a certain interpretation of what to say. (Mokhtari \& Reichard, 2002).

\subsubsection{Linguistic Representation}

The last types of text mode is written language representation in which the text plays role to represent meaning to another through writing and to represent meaning to oneself through reading in the form of handwriting, a printed page, and a screen page.
Table 3. Overall analysis of metacognitive reading strategies in linguistic representation

\begin{tabular}{ccc}
\hline $\begin{array}{c}\text { Reading Strategies } \\
\text { Subscale }\end{array}$ & $\begin{array}{c}\text { Overall } \\
\text { Mean (M) }\end{array}$ & $\begin{array}{c}\text { Overall Std. } \\
\text { Deviation (SD) }\end{array}$ \\
\hline $\begin{array}{c}\text { Global Reading } \\
\text { Strategies }\end{array}$ & 3.83 & 0.82 \\
$\begin{array}{c}\text { Problem Solving } \\
\text { Strategies }\end{array}$ & $\mathbf{3 . 9 6}$ & 0.73 \\
$\quad$ & 3.66 & \\
$\begin{array}{c}\text { Support Reading } \\
\text { Strategies }\end{array}$ & & 0.87 \\
\hline
\end{tabular}

This section presented and discussed students' analysis of variance of perceived strategy use by reading ability of low proficient students preferably on their reading strategies toward written language of text mode. The quantitative data collected through the same instrument as the previous text representation from 10 students who were representatively administered, exhibited in Table 3.

In general, Table 3 indicates that low achieving students has demonstrated a preference for using problem-solving reading methods $\mathrm{M}=3.96$ ) as the highest score derived from the average mean score. In addition, it provides sufficient information about the overall tendency of the low achieving students' reported strategy use in reading written language text mode. It shows the high use of problem-solving reading strategies which was similar with the previous text representation. It could be guaranteed that low achieving students were aware of their strategies while reading and made use of them frequently to monitor their reading comprehension. 10 students tend to use problem solving strategies, global reading strategies and support reading strategies, and this is often supported when learners actually read academic texts in a written language. In details the problem-solving strategies obtained the highest average mean score $(M=3.96)$ resulting in a high degree of awareness. It indicates that low achieving students performed an overwhelming preference on problem solving strategy which was being more significant than the two rest strategies which were global reading strategy $(\mathrm{M}=3.83)$ which placed the second stage and continued by support reading strategies $(M=3.66)$ as the last stage of the stratification of numbers. It also indicates that high and low achieving students activated their metacognitive reading strategies in high intention with a little bit different in numbers. It includes how students re-read the text for better understanding, go back to every sentence or paragraph, pause and stop while reading intended to read slowly and carefully and to adjust reading rate, visualize information obtained while reading, and many 
other activities which define problem solving strategies they employed to understand written language text modes. This result is consistent with the results in Mokhtari and Reichard (2002) and Mónos (2004) research, which indicate that problem-solving strategies collapse into high-use and support reading strategies is the least widely used by students in three categories.

Those overall result then confirms that in the practical use of strategies in reading text in linguistic mode, low achieving students cohesively activate their strategy in frequent and effective ways appropriate to the visual texts. Looking deeper to the number of average use of certain strategies, problem solving and global reading strategies, this study indicates that they were activated more often when the students read linguistic text mode. Accordingly, in ascending order, both groups had the same strategies order. The findings supported that of Mistar's (2001) conducting a study on learning strategies through variations, which showed that both good and less skilled EFL students in Indonesia used similar strategies, but the good ones used the strategies more often and successfully than fewer students did when reading the text.

\section{CONCLUSION}

The findings of this study described the student's metacognitive reading strategies by low achieving students which resulted from the several different text modes during reading multimodal texts. No difference dominant strategy uses by low achieving students towards the three different text modes attempt. Considering the score numbers of each strategy, activated by the low students, this study then indicates the regardless of students' proficiency level on employing metacognitive reading strategies realizing on statistical findings of several text modes.

On the one hand, this study then proposed and discussed reading texts used as an example of the variety of reading instructions implemented in the classroom for students and students' experiences when activating their strategic actions during reading multimodal texts. The various reading instructions used which stimulate and maximize students' learning styles to be successful multimodal readers in 21 st-century learning is highly recommended. Teachers can help their students to recognize the power of using metacognitive reading strategies before, during, and after reading comprehension activity to get fully meaningful comprehension and to make learning quicker, more comfortable, and more effective.

Although this study is limited to only low achieving multimodal readers, it contributes to the body of research on the development of literacy instruction for multimodal texts, as well as to the literature on the roles of multimodal text readers. In light of the findings of this study, this study suggests more future investigation into the contribution of representation modes to the implementation of the skills of multimodal text reading as evidenced by students' reading performance and reading strategies.

\section{REFERENCES}

Al-Issa. (2006). Schema theory and L2 reading comprehension: Implications for teaching. Journal of College Teaching \& Learning (TLC), 3(7), 4148. https://doi.org/10.19030/tlc.v3i7.1700

Anderson, N. (2003). Scrolling, clicking, and reading English: Online reading strategies in a second/foreign language. The Reading Matrix, 3(3).

Anwar, M. N., Shamim-ur-Rasool, S., \& Haq, R. (2012). A comparison of creative thinking abilities of high and low achievers secondary school students. International Interdisciplinary Journal of Education, 1(1), 3-8.

Artelt, C., Weinert, S., \& Händel, M. (2013). Assessing metacognitive knowledge: Development and evaluation of a test instrument Erfassung metakognitiven Wissens: Entwicklung und Evaluation eines Testinstruments Zusammenfassung. Journal for Educational Research Online Journal Für Bildungsforschung Online, 5(2), 162-188.

Chen, K. T. C., \& Chen, S. C. L. (2015). The use of EFL reading strategies among high school students in Taiwan. The Reading Matrix: An International Online Journal, 15(2), 156-166.

Chevalier, T. M., Parrila, R., Ritchie, K. C., \& Deacon, S. H. (2017). The role of metacognitive reading strategies, metacognitive study and learning strategies, and behavioral study and learning strategies in predicting academic success in students with and without a history of reading difficulties. Journal of Learning Disabilities, 50(1), 34-48. https://doi.org/10.1177/0022219415588850

Harsiati, T. (2018). Karakteristik soal literasi membaca pada program Pisa. Litera, 17(1), 90-106. https://doi.org/10.21831/ltr.v17i1.19048

Lander, J. A., \& Brown, H. D. (1995). Teaching by principles: An interactive approach to Language Pedagogy. $\quad$ Language, $71(4), \quad 843$. https://doi.org/10.2307/415773

Leu, D. J., McVerry, J. G., O’Byrne W. I., Kiili, C., Zawilinski, L., Everett-Cacopardo, H., Kennedy, C., \& Forzani, E. (2011). The new literacies of online reading comprehension: Expanding the literacy and learning curriculum. Journal of Adolescent \& Adult 
Literacy, 55(September), https://doi.org/10.1598/JA

Liu, J. (2013). Visual images interpretive strategies in multimodal texts. Journal of Language Teaching and Research, 4(6), 1259-1263. https://doi.org/10.4304/jltr.4.6.1259-1263

Mistar, J. (2001). English learning strategies of Indonesian university students across individual differences. Asian Journal of English Language Teaching, 11, 19-44.

Mónos, K. (2004). Learner strategies of Hungarian secondary grammar school students. Budapest, Hungary: Akademiai Kiado.

Mohamed, A. R., Chew, J., \& Kabilan, M. K. (2006). Metacognitive reading strategies of good Malaysian Chinese learners. Malaysian Journal of ELT Research, 2(1), 21-41.

Mokhtari, K., \& Reichard, C. A. (2002). Assessing students' metacognitive awareness of reading strategies. Journal of Educational Psychology, 94(2), 249-259. https://doi.org/10.1037/00220663.94.2.249
Nguyen, C. D., \& Newton, J. (2018). Schemata in listening comprehension. The TESOL Encyclopedia of English Language Teaching, 1-7. https://doi.org/10.1002/9781118784235.eelt0592

Nunan, D. (2003). The impact of English as a global language on educational policies and practices in the Asia-Pacific region. TESOL Quarterly, 37(4), 589. https://doi.org/10.2307/3588214

Serafini, F. (2012). Expanding the four resources model: Reading visual and multi-modal texts. Pedagogies, $7(2)$, 150-164. https://doi.org/10.1080/1554480X.2012.656347

Sinambela, E., Manik, S., \& Pangaribuan, R. E. (2015). Improving students' reading comprehension achievement by using K-W-L strategy. English Linguistics Research, 4(3), 13-29. https://doi.org/10.5430/elr.v4n3p13

Suherdi, D. (2015, November). English for $21^{\text {st }}$ century Indonesia. In English Education International Conference (EDUTICON). 